\title{
Tempos e linguagens. Representações e inter-relações
}

Maria Ignês Carlos Magno

Doutora em Ciências da Comunicação pela ECA/USP.

Professora do curso de Pedagogia do Centro Universitário Salesiano

de São Paulo e da Universidade Anhembi Morumbi.

E-mail: unsig@globo.com

A racionalidade construída ao longo dos séculos XVIII e XIX aprimorou nosso olhar em perspectiva e nos ensinou a entender o conhecimento de forma fragmentada. Quanto mais as ciências aprofundavam os estudos os homens, a natureza, a própria ciência, a sociedade, as artes, trazendo inegáveis avanços e benefícios em diferentes áreas e linguagens, aumentava-se a distância entre esses temas e a possibilidade de entendê-los como partes de um todo e de perceber suas interferências na construção do conhecimento. A vitória de um modelo de escola positivista reforçou ainda mais tal leitura compartimentada da produção humana, dificultando a percepção das inter-relações existentes entre as diferentes áreas, linguagens, temas e representações do mundo.

Como o interessante está exatamente em perceber as conexões, e também em apreender a permanência de alguns temas ao longo dos tempos, proponho para este número da revista três filmes que permitem um exercício sobre as relações mútuas entre períodos históricos, linguagens artísticas e temários. Os filmes são: Moça com Brinco de Pérola (século XVII), Frankenstein de Mary Shelley (século XIX) e Blade Runner (século XX).

O primeiro filme é sobre o pintor holandês Johannes Vermeer e o segundo, sobre a escritora inglesa Mary Shelley. O terceiro filme, embora não seja adaptação de romance ou trate da vida de um artista em especial, servirá como parte da referência temática que perpassa os tempos, as artes e as ciências: a discussão entre criador e criatura e a contemporaneidade histórica. 


\section{FICHA TÉCNICA}

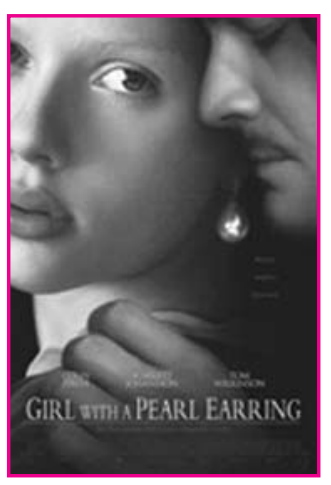

Moça com Brinco de Pérola

Título original - Girl with a Pearl Earring

Gênero - Drama

Roteiro - Olivia Hetreed, baseado no livro de Tracy Chevalier

Direção - Peter Webber

Produção - Andy Paterson e Anand Tucker

Direção de fotografia - Eduardo Serra

Desenho de produção - Bem van Os

Direção de arte - Christina Schaffer

Ano - 2003

Duração - 95 minutos

Em pleno século XVII vive Griet, uma jovem camponesa holandesa. Devido a dificuldades financeiras, ela é obrigada a trabalhar na casa de Johannes Vermeer, um renomado pintor de sua época. Aos poucos Johannes começa a prestar atenção na jovem de 17 anos, fazendo dela sua musa inspiradora para um de seus mais famosos trabalhos: a tela "Girl with a Pearl Earring".

\section{HISTÓRIA E ARTE}

Johannes Vermeer nasceu em 1632, em Delft, na Holanda, tranqüila cidade cortada por canais e famosa por sua porcelana. No entanto, se a cidade como seus quadros não deixam transparecer a agitação histórica, é importante sabermos que "sua época foi agitada por guerras em que a Holanda, além de conquistar seu território ao mar, conquistava também a soberania nos campos de batalha, enfrentando a Espanha, a França, a Inglaterra, a Suécia e a Dinamarca"1.

No tocante a sua produção artística, é interessante sabermos que ela se encontra no limiar entre o Barroco, a Reforma e a Contra-Reforma. Do Barroco, Vermeer mantém a filiação a Caravaggio e os aspectos plásticos. Mas, no jogo sutil da luz e da cor, intervém uma sensibilidade particular. Sua arte é feita com rigor e uma arquitetura espiritual e secreta. Segundo estudiosos de arte, a pintura de Vermeer representa, entre outros aspectos, uma reação à influência de maneirismos franceses e italianos, ao retomar o caudal da tradição holandesa, ou seja, a arte doméstica. Retoma-a e eleva-a a um nível de limpidez e de poesia estranhamente aliciante ${ }^{2}$.

É claro que Vermeer não é só isso. Trata-se apenas de uma entrada para que o professor, além de desenvolver, a partir da arte, uma pesquisa, um projeto e mesmo o ponto inicial de um estudo sobre as lutas religiosas, a Reforma

1. COLEÇÃO GÊNIOS DA PINTURA. São Paulo: Abril Cultural, 1969. Volume IV - Do Barroco ao Neoclassicismo, e Volume V - Do Romantismo ao Impressionismo.

2. Ibid. protestante, a Contra-Reforma, as características da Reforma e do capitalismo assumidas em diferentes países, possa também relacionar e/ou retomar o estudo sobre a ética protestante e a lógica do capitalismo ao enfocar a Holanda; possa, ainda, ligar a história holandesa com a expansão capitalista no mundo colonial português e espanhol, ou ainda com a Contra-Reforma e a Inquisição. No tocante à Inquisição, à pintura de Vermeer e à filosofia, é essencial termos 
noção de que Spinoza, filósofo judeu, expulso de Portugal durante a Inquisição, foi para a Holanda, entrou em contato com a obra de Vermeer e é considerado pelos críticos de arte como aquele que melhor definiu a obra do pintor. Spinoza escreveu: "São os objetos que fazem com que tenhamos percepção. Somos influenciados tanto pelo repouso como pelo movimento que os compõem" Mas não foi apenas Spinoza que escreveu sobre Vermeer; podemos também pesquisar sobre o entusiasmo de Vincent van Gogh pelo quadro Mulher em Azul e de Marcel Proust, que, diante do quadro Vista de Delft, escreveu: "É a visão de uma beleza que basta a si mesma"4.

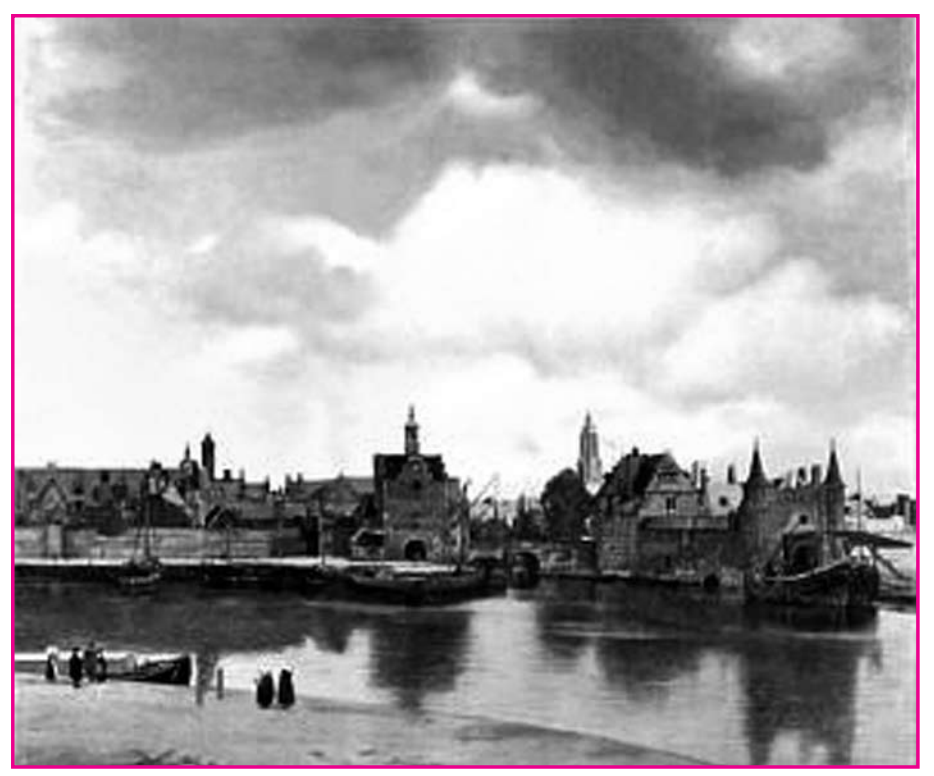

Vista de Delft, Johannes Vermeer (1660).

Especificamente sobre o filme, caberá ao(s) professor(es) e seus alunos assistirem ao filme e fazerem a leitura dele. Sugiro apenas que observem dois aspectos: a fotografia e a relação do pintor com a personagemempregada, que foi a Moça com Brinco de Pérola, seu mais famoso quadro. Além do tom intimista próprio do autor, que revela uma ambígua relação entre eles, observem a sensibilidade e o apurado senso estético da personagem, que era filha de um ceramista de Delft.

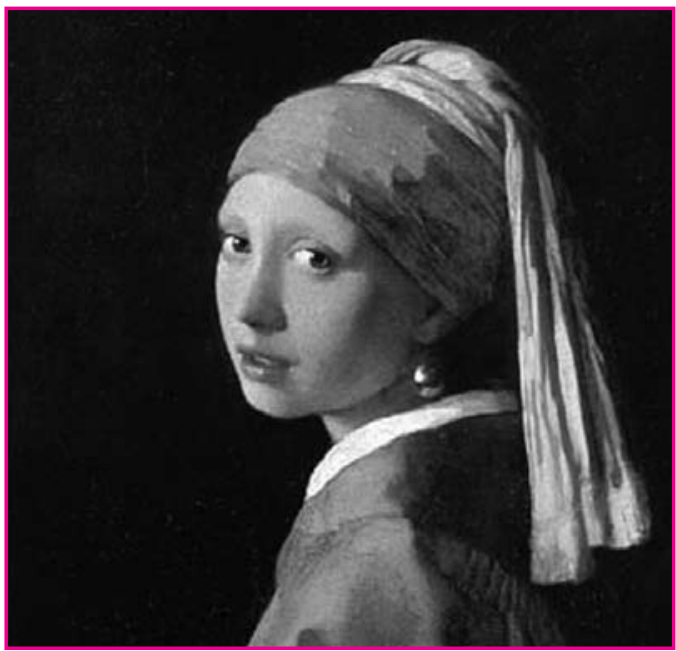

Moça com Brinco de Pérola, Johannes Vermeer (1665). 


\section{FICHA TÉCNICA}

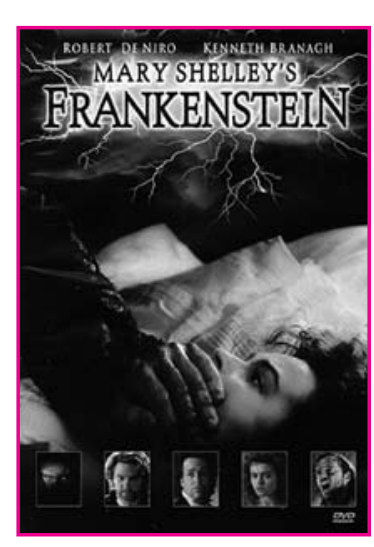

Frankenstein de Mary Shelley

Título original - Mary Shelley's Frankenstein

Roteiro - Steph Lady e Frank Darbont, baseado

no livro de Mary Shelley

Direção - Kenneth Branagh

Produção - Francis Ford Coppola, James V. Hart e John Vei-

Música - Patrick Doyle

Direção de fotografia - Roger Pratt

Desenho de produção - Tim Harvey

Direção de arte - Martin Childs, Desmond Crowe e John Fen-

Ano - 1994

Duração - 118 minutos

LC

Em 1794, um explorador no Ártico tenta abrir caminho através do gelo e encontra Victor Frankenstein. Logo depois os cães decidem atacar uma criatura, que os mata rapidamente. Assim, Victor decide contar-lhe como tudo começou, quando foi estudar medicina em Ingolstadt, deixando para trás sua noiva e levando consigo uma única obsessão: vencer a morte. Na faculdade, ao discordar de um renomado mestre, acaba chamando a atenção de outro, que revela seus experimentos em reanimar tecidos mortos. No entanto, esse pesquisador é assassinado e o culpado pelo crime, enforcado. Então, Victor decide colocar o genial cérebro do mestre no vigoroso corpo do assassino, mas as conseqüências de tal ato seriam inimagináveis.

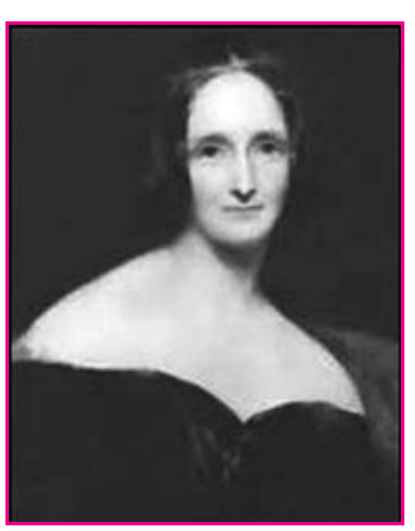

Mary Shelley

\section{ARTE, HISTÓRIA E CIÊNCIA}

Mary Wollstonecraft Shelley (1797-1851) era filha de Mary Wollstonecraft, considerada a primeira feminista, pois influenciou os movimentos iniciais de emancipação da mulher. Morreu onze dias depois de dar à luz gêmeos, Mary Shelley e Willian Godwin, este poeta e ensaísta que abandonou a vida eclesiástica e se tornou um pensador reformista radical. Foi por meio de seu pai que Mary se aproximou desde cedo dos intelectuais ligados ao movimento romântico.

Os anos de 1814-1819 representam um momento de falência e de refluxo do império napoleônico.

5. COLI, Jorge. O fascínio de Frankenstein. Folha de S. Paulo, São Paulo, 2 junho 2002. Caderno Mais.
De acordo com o prof. Jorge Coli, "na virada do século XVIII para o século XIX, há um deslocamento do lugar onde se encontra o humano. Surge uma nova configuração, onde o olhar do homem sobre o homem não é mais sobre si, mas sobre uma coisa" ${ }^{5}$. Objeto em si, seu corpo se evidencia, apresenta-se como corpo apenas, disposto para a ciência e para a arte. 
Entre o contexto histórico e o desenvolvimento das ciências, Mary Shelley, após uma noite de discussões filosóficas e científicas com amigos intelectuais que, durante as noites pouco propícias para sair, ficavam lendo histórias fantasmagóricas e discutindo teorias científicas, criou Frankenstein ou o Moderno Prometeu $^{6}$. O galvanismo, conjunto de fenômenos de natureza eletroquímica que se passam em sistemas constituídos por metas diferentes postos em contato com eletrólitos, foi uma das discussões teóricas daquela noite.

O romance, que teve origem num conto escrito em uma noite de 1818, trouxe Victor como um herói mitológico, Prometeu, que tentou alcançar o segredo proibido. Mas diferentemente do Prometeu da mitologia grega, ele busca auxílio na ciência moderna.

Como todos conhecem o personagem, eternizado pelo cinema em diferentes momentos e interpretações, mas poucos leram a obra original de Mary Shelley, torna-se um bom momento para desenvolver o estudo específico sobre a estrutura, os personagens, o foco narrativo, as questões de tempo e espaço, entre outros aspectos literários da obra, bem como sobre a mitologia grega, em especial o mito de Prometeu Acorrentado.

Se quisermos ter uma idéia mais fina das relações entre arte e ciência e de suas interferências, vale a pena estudar a seqüência em que Victor produz sua criatura, fazendo um exame minucioso da fisiologia humana, dos desenhos e do local descrito por Mary Shelley e reproduzido no filme: um "grande ateliê, igual aos de restauração que formavam estátuas de partes diversas"7. Frankenstein, segundo Jorge Coli, liga arte e ciência, a imagem cristalina e o cadáver repugnante, a violência e o sofrimento. Ele incorpora um projeto monstruoso, uma ambigüidade humana, muito humana; mostra as virtudes da imperfeição.

Um outro exemplo das relações entre história, arte e ciência que podemos

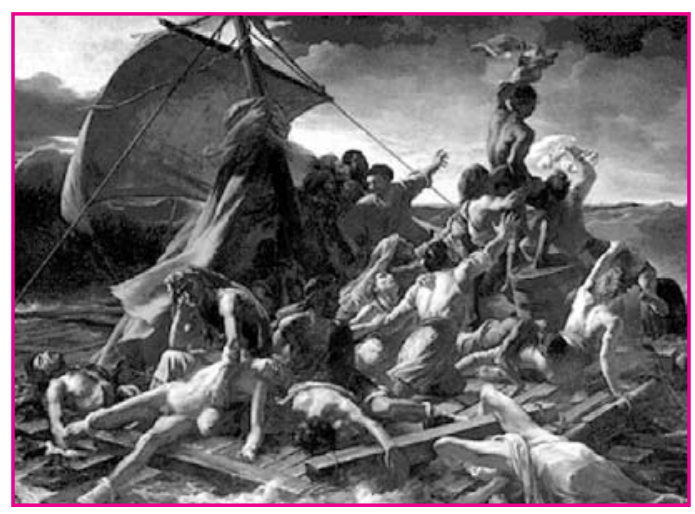

A Balsa da Medusa, Théodore Géricault (1819). recuperar para exemplificar o período estudado é a pintura de Théodore Géricault, em especial A Balsa $d a$ Medusa, produzida entre os anos de 1817 e 1819.

A Medusa era uma fragata do governo francês que, repleta de colonos, naufragou em uma tempestade ao largo da costa africana, nas proximidades de Cap Blanch, em conseqüência, segundo se afirmou, da incompetência do comandante.

Profundamente comovido pelo desastre, Géricault (1791-1824) selecionou um momento especialmente desesperador, em que o grupo de sobreviventes acena por socorro para um navio que passa ao longe, sem vê-los. Quase cento e cinqüenta sobreviventes amontoados na balsa vagaram à deriva durante doze dias, dos quais apenas quinze conseguiram sobreviver.

6. <http://www.mundo cultural.com.br> (Literatura, link análises literárias).

7 COLI, Jorge. Op. Cit. 
Através de entrevistas com alguns náufragos e de reportagens dos jornais sobre a tragédia, Géricault reuniu um macabro mosaico de canibalismo, insubordinação e prolongado tormento físico e psicológico. Obteve corpos na morgue a fim de estudar as diferentes fases de decomposição e, em um hospital, desenhou os rostos de pessoas tresloucadas pelo sofrimento. Construiu um modelo de balsa em seu ateliê, no Havre, e estudou os movimentos das ondas. Sua intenção era combinar o sentimento suscitado pelo caráter imediato do evento real com a monumentalidade da pintura histórica. Uma composição piramidal barroca de mortos e corpos agonizantes termina na figura de um sobrevivente negro acenando por socorro; o claro-escuro dramático sublinha os extremos de desespero e de esperança ${ }^{7}$.

Géricault era contemporâneo de Mary Shelley. Seu quadro foi exposto em 1819, na mesma época de Frankenstein. A obsessão pelos corpos levou o pintor, a pedido do amigo e psiquiatra Étienne Georget, pioneiro na França no tratamento de doentes emocionais, a retratar em uma clínica a insanidade mental. Os seus retratos estão entre os mais poderosos exemplos de representação psicológica de toda a história da arte ocidental. Um exemplo a ser estudado é o quadro A louca.

Embora Géricault não esteja diretamente relacionado com os filmes expostos, vale como parte do exercício, porque permite um estudo comparativo entre a literatura, as artes plásticas e ciência no século XIX. Enquanto Mary Shelley descreve o laboratório de Victor como se fosse um ateliê, Géricault anda pelos necrotérios estudando corpos em decomposição para melhor retratar seus personagens nos quadros.

Retomando o cinema - que ao "lado da fotografia trata de uma forma de arte que surgiu no primeiro impulso do modernismo cultural, mas também porque dentre as formas artísticas, ele tem talvez a capacidade mais robusta de tratar de maneira instrutiva temas entrelaçados do espaço e do tempo" ${ }^{-}$-, podemos iniciar o diálogo com Blade Runner e a comunicação que este faz com a história, com a ciência e, principalmente, com Mary Shelley.

8. REYNOLDS, Donald. A arte do século XIX. São Paulo: Linoart Ltda. Licença editorial para o Círculo do Livro por cortesia de Zahar Editores S.A. s/d.

\section{FICHA TÉCNICA}

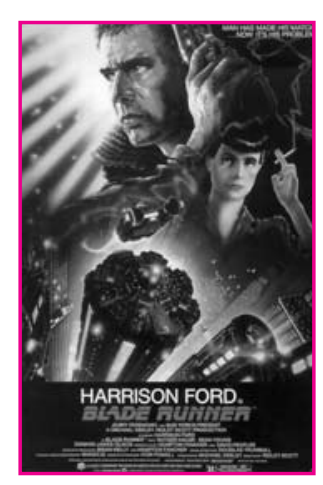

Blade Runner

Roteiro - Hampton Fancher

Direção - Ridley Scott

Produção - Michael Deeley/Ridley Scott

Direção de fotografia - Jordan Cronenweth

Música - Vangelis

Ano - 1982

Duração - 117 minutos

LG 
Por volta de 2019 (em Los Angeles), o planeta Terra está em total decadência. Os poucos habitantes vivem aglomerados em gigantescos arranha-céus. A engenharia genética se tornou uma das maiores indústrias, criando os replicantes, criaturas dotadas de força e inteligência, praticamente indistinguíveis dos seres humanos. O filme gira em torno da investigação do especialista Deckard, encarregado de descobrir replicantes e eliminá-los ou retirá-los de circulação. Seu tempo de vida: quatro anos.

\section{HISTÓRIA E CIÊNCIA NO CINEMA PÓS-MODERNO}

Blade Runner é considerado uma parábola de ficção científica sobre temas pós-modernos, situados num contexto de acumulação flexível e de compressão do tempo-espaço contemporâneos. Historicamente, apresenta algumas das características e as contradições de um mundo globalizado, em que convivem paisagens em decadência e um universo de alta tecnologia; o hibridismo cultural e lingüístico; a fragmentação da vida social, o caos dos signos, das mensagens; a engenharia genética e "o comércio mais humano do que humano é o nosso negócio”, fala do dono da Tyrell Corporation, responsável, entre outras coisas, por produzir os replicantes que trabalham em tarefas altamente especializadas e difíceis nas fronteiras da exploração espacial ${ }^{10}$.

Artisticamente, ao mesmo tempo que é considerado um filme pós-moderno e contemporâneo, pode ser lido também em suas características barrocas, não apenas pela oposição entre claro e escuro, mas, e principalmente, porque trabalha as fronteiras.

Sabemos que Blade Runner pode ser explorado em diferentes aspectos da história e da arte pós-moderna, como, por exemplo, na arquitetura. Mas para este momento e exercício foi usado para mostrar um dos temas que permanecem na história desde Prometeu e que vem se intensificando ao longo do desenvolvimento das ciências biológicas e das revoluções tecnológicas: o tema da criação.

Para tal discussão, sugiro que duas seqüências de ambos os filmes sejam trabalhadas: primeiro, aquela em que a criatura Frankenstein se encontra com Victor na caverna e trava com seu criador um diálogo sobre a própria criação, sobre seus sentimentos, sobre a matéria da qual fora criado e pede uma companheira, porque não agüenta a solidão. A segunda seqüência é a do encontro do replicante Roy, líder da rebelião dos Nexus 6, com seu criador, o dono da Tyrell Corporation, especializada em engenharia genética. Ao encontrar o "pai", beija-o e em seguida trava diálogo sobre criação, vida e morte. Nesse diálogo, entre outras discussões, podemos traçar as mudanças e a evolução das pesquisas no campo da engenharia genética e dos possíveis desdobramentos da ciência humana.

Outras aproximações e comparações que podemos traçar entre tempos e espaços é a própria concepção de tempo e de espaço nos três filmes e nas linguagens específicas de cada um deles. As artes plásticas, a literatura e o cinema tornam-se um meio de conhecimento da história e da revelação do humano. 
Resumo: A autora observa que a racionalidade construída ao longo dos séculos XVIII e XIX aprimorou nosso olhar em perspectiva e nos ensinou a entender o conhecimento de forma fragmentada. Quanto mais as ciências aprofundavam os estudos trazendo inegáveis avanços e benefícios em diferentes áreas e linguagens, aumentava-se a distância entre esses temas e a possibilidade de entendê-los como partes de um todo e de perceber suas interferências na construção do conhecimento. Para que se notem essas conexões, e também se apreenda a permanência de alguns temas ao longo dos tempos, propõe três filmes que permitem um exercício sobre as inter-relações entre períodos históricos, linguagens artísticas e temários: Moça com Brinco de Pérola (século XVII), de Peter Webber; Frankenstein de Mary Shelley (século XIX) de Kenneth Branagh e Blade Runner de Ridley Scott (século XX). Outras aproximações e comparações sugeridas pela autora vêm da própria concepção de tempo e de espaço nos três filmes e nas linguagens específicas de cada um deles. As artes plásticas, a literatura e o cinema tornam-se um meio de conhecimento da história e da revelação do humano.

Palavras-chave: cinema, história, literatura, linguagem cinematográfica.
Abstract: The author observes that the rationality built along the XVIII and XIX centuries perfected our look in perspective and lead us to understand the knowledge in a fragmentary way. The more sciences deepened their studies bringing advances and benefits in different areas and languages, the more the distance between these subjects and the possibility of understanding them as parts of a whole and perceive their interferences in the knowledge process was increased. To perceive these connections, this article proposes the work with three motion pictures that will allow an exercise relating historical periods, artistic languages and themes: Girl with a Pearl Earring (XVII century), by Peter Webber; Mary Shelley's Frankenstein (XIX century), by Kenneth Branagh; and Blade Runner, by Ridley Scott (XX century). Other approaches and comparisons suggested by the author are the conception of time and space in these pictures and the specific languages in each of them. Plastic arts, literature and cinema become a way of knowing history and revealing the human nature.

Keywords: cinema, history, literature, cinematographic language. 